\title{
MANAJEMEN FASILITAS AIR CONDITIONER MASJID BAITUL IHSAN BANK INDONESIA SURABAYA
}

\author{
Mauludi \\ Sekolah Tinggi Ilmu Dakwah dan Komunikasi Islam (STIDKI) Ar-Rahmah, Jl. Teluk Buli I/5- \\ 7 Surabaya 60165, Jawa Timur \\ e-mail: mauludi@stidkiarrahmah.ac.id
}

\begin{abstract}
In order to improve the comfort of worship for the congregation, the Baitul Ihsan Mosque of Bank Indonesia provides air conditioner (AC) facilities. These facilities are central and always function well, so as to increase the satisfaction and preoccupation of the congregation. This study aims to determine the management of the AC facility management carried out by the Baitul Ihsan BI Mosque. The research method used is through observation, interviews, and documentation. The data analysis of this research was conducted in a descriptive qualitative manner. The results showed that the management of air conditioning facilities at the Baitul Ihsan Mosque was carried out from the planning to evaluation stages. There are several parties that have been ignorant, namely the BI, the mosque, and the AC maintenance service. Good coordination makes the AC performance at the Baitul Ihsan Mosque function optimally, so that the congregation feels satisfied.
\end{abstract}

Keywords: Facility management, Masjid Baitul Ihsan Bank Indonesia, mosque management

\begin{abstract}
ABSTRAK
Demi meningkatkan kenyamanan ibadah para jama'ahnya, Masjid Baitul Ihsan Bank Indonesia menyediakan fasilitas air conditioner (AC). Fasilitas tersebut bersifat sentral dan selalu berfungsi dengan baik, sehingga dapat meningkatkan kepuasan dan kekhusyukan para jama'ah. Penelitian ini bertujuan untuk mengetahui manajemen pengelolaan fasilitas AC yang dilakukan oleh pihak Masjid Baitul Ihsan BI. Metode penelitian yang digunakan adalah melalui obvervasi, wawancara, dan dokumentasi. Analisis data penelitian ini dilakukan secara deskriptif kualitatif. Hasil penelitian menunjukkan bahwa manajemen fasilitas AC di Masjid Baitul Ihsan dilakukan mulai dari tahap perencanaan hingga evaluasi. Terdapat beberapa pihak yang terbilat, yaitu pihak BI, pihak masjid, dan pihak jasa layanan perawatan AC. Koordinasi yang baik membuat performa AC di Masjid Baitul Ihsan berfungsi optimal, sehingga para jama'ah merasa puas.
\end{abstract}

Kata kunci: Manajemen fasilitas, manajemen masjid, Masjid Baitul Ihsan Bank Indonesia

\section{PENDAHULUAN}

Fasilitas adalah segala sesuatu yang sengaja disediakan oleh penyedia jasa untuk dipakai dan dinikmati oleh konsumen. Menurut Lupioadi fasilitas merupakan penampilan, kemampuan sarana prasarana, dan keadaan lingkungan sekitar dalam menunjukkan eksistensi suatu lembaga kepada eksternal. Tjiptono menyatakan bahwa fasilitas juga dapat mempengaruhi pembentukan presepsi konsumen terhadap kualitas jasa yang diberikan oleh 
lembaga. ${ }^{1}$ Oleh karena itu, penting bagi suatu lembaga untuk melakukan pengelolaan fasilitas yang dimiliki, sehingga dapat memberikan tingkat kepuasan yang maksimal kepada konsumen.

Meskipun fungsi utama mesjid sebagai tempat mendirikan ibadah shalat berjama ${ }^{e e} a h$, tetapi bukan berarti masjid hanya tempat melaksanakan shalat saja. Masjid di masa Rasulullah selain digunakan untuk shalat, berzikir, beriktikaf dan membaca al-Quran juga dipergunakan untuk kepentingan pendidikan dan sosial. Misalnya sebagai tempat belajar dan mengajar kebaikan, merawat orang sakit, menyelesaikan permasalahan umat Islam dan memutuskan hukum, mengatur strategi perang dan lain sebagainya

Pada masa sekarang masjid perlu diperluas fungsinya serta diurus dengan manajemen yang baik. Menurut Sidi Gazalba sebagaimana disebutkan oleh Azhari Bashar, beberapa fungsi strategis masjid adalah:

1. Sebagai pusat pendidikan umat, untuk meningkatkan dan pengembangan ilmu kaum muslimin, terutama ilmu agama Islam

2. Tempat musyawarah untuk memecahkan berbagai persoalan yang timbul dalam masyarakat

3. Tempat membina keutuhan dan solidaritas umat untuk mewujudkan kebersamaan, kesetaraan dan kegotongroyonngan dan mencegah perpecahan dan keretakan umat

4. Tempat pembinaan dan pengkaderan pemimpin-pemimpin umat

5. Pada masa Rasulullah dan sahabat-sahabatnya masjid juga dijadikan tempat pengaturan kenegaraan dan strategi perang

6. Tempat pengembangan kebudayaan Islam seperti seni baca Al-Quran, Dalail Khairat, Seni Khaligrafi dan Arsitektur Islam.

Masjid Baitul Ihsan merupakan salah satu masjid perkantoran di Surabaya, tepatnya di Bank Indonesia (BI). Masjid ini berdisi sejak 21 Juli 2006 M dan diresmikan oleh Gubernur Bank Indonesia. ${ }^{2}$ Demi meningkatkan kenyamanan ibadah para jama'ahnya, pihak masjid menyediakan berbagai fasilitas penunjang yang salah satunya berupa air conditioner (AC). Fasilitas AC yang tersedia di Masjid Baitul Ihsan BI bersifat sentral seperti layaknya gedung perkantoran dan selalu berfungsi dengan baik, sehingga dapat meningkatkan kepuasan dan kekhusyukan para jama'ah dalam melakukan segala aktifitas ibadahnya. Penelitian ini bertujuan untuk mengetahui manajemen pengelolaan fasilitas AC yang dilakukan oleh pihak Masjid Baitul Ihsan BI. Hasil penelitian yang diperoleh diharapkan dapat menjadi sumber rujukan bagi para pengurus masjid lainnya dalam mengelola fasilitas masjid.

\section{METODE PENELITIAN}

Penelitian ini dilakukan di Masjid Baitul Ihsan BI, Jalan Pahlawan No. 105 Surabaya, Jawa Timur pada bulan Oktober 2018. Metode penelitian yang digunakan untuk mengumpulkan data adalah melalui obvervasi, wawancara, dan dokumentasi. Narasumber pada penelitian ini adalah pengurus Masjid Baitul Ihsan BI yang bertanggung jawab langsung

\footnotetext{
${ }^{1}$ Indra Lutfi Sofyan,dkk., Pengaruh Fasilitas dan Kualitas Pelayanan Terhadap Loyalitas, Diponogoro jurnal of social and politic tahun $2013 \mathrm{hlm} .3$

2 Mubarrok, H., Thoha, A.F.K., dan Hakim, A.K. 2019. Strategi Masjid Baitul Ihsan Bank Indonesia Jawa Timur dalam Membangun Loyalitas Murid TPQ. Jurnal Masjiduna, 2(2): 56-63.
} 
terhadap manajemen fasilitas masjid. Analisis data penelitian ini dilakukan secara deskriptif kualitatif.

\section{HASIL DAN PEMBAHASAN}

Dalam penyajian data ini, peneliti akan menggambarkan atau mendeskripsikan data yang telah di dapatkan peneliti dari hasil wawancara dan dokumentasi. Hal tersebut bertujuan untuk membantu keabsahan data atau kevaliditasan data yang disajikan. Adapun data yang diperoleh dari penelitian ini, yaitu mengenai Manajemen Fasilitas Air Conditioner Masjid Baitul Ihsal Bank Indonesia Jalan Pahlawan Surabaya. Dalam penyajian data ini, peneliti akan menyajikan data tentang proses perawatan atau pemeliharaan AC di Masjid Baitul Ihsan Bank Indonesia, sebagai berikut :

\subsection{Pola manajemen perawatan di Masjid Baitul Ihsan Bank Indonesia Surabaya 1. Perencanaan (planning)}

Perencanaan merupakan salah satu aspek dari pembentukan organisasi untuk tercapainya sesuatu tujuan yang diinginkan, pengurus dan khususnya staf di bagian teknisi AC mempersiapkan segala sesuatu yang terkait saat proses pengoprasian baik dari format pelaksanaan, anggaran dana yang di butuhkan dan jumlah orang-orang yang terlibat dalam pengoprasian AC tersebut. Berdasarkan hasil observasi diperoleh data terkait perencanaan pengroprasian dan perawatan AC di Masjid Baitul Ihsan Bank Indonesia Surabaya, kebetulan salah satu pengurus takmir Masjid Baitul Ihsan juga mendapat amanah di bagian logistic dan cukup paham terkait AC di gedung BI.

"Untuk pengadaan yaa,jadi untuk perencaaan sistem pendingin gedung itu,kalo di kitakan karna AC nya sudah ada tuh berartikan pemeliharaanya tetep ada kontrak tetep ada,planning tetep ada, sistemnya kayak tender untuk pemeliharann,namun untuk pengadaan karana umurnya AC central itukan mirip mirip sama umurnya gedung kantor kurang lebih 20 tahun untuk ac central itu maksudnya untuk ganti baru jadi mesti atau aturan dikita kurang lebih 20 tahun itu pengadaannya melalui kantor pusat pengadaan baru, kalo pengadaaan baru ya, karena kenapa kantor pusat, pertama nilainya itu masuk ke nilai investasi, kan AC central itu harganya kan ngga cukup 100-200 juta, satu chiler itu harganya pas saya masuk di BI itu tahun 2012 itu haraganya satu itu harganya 1 komaa, 1,5 M itu baru 1, belum lagi nanti kalo 5, itu harga pada saat tahun itu, yakan liat dari kondisi upahnya berapa terus dolarnya berapakan gitu jadi nilai kayak gitu sudah wewenangnya kantor pusat apalagi merombak seluruh instalasi jadi model tendernya lelang tapi di bikin model paket karna nilainya cukup gede kalo di tafsir sih untuk chilernya aja misalkan $2 \mathrm{M}$ yaa $2 \times 5$ $10 \mathrm{M}$ belum instalasi, belum AHUnya kira kira di atas 10M. Sebelum pengadaan tetep ada assesement dari tim kantor pusat dan mungkin dari upraisor atau dari rensalten ini kira kira masih layak atau ngga soalnya mohon maaf barang barang sekarang kwalitasnya tuh beda sama barang barang dulu contoh kwalitas plat yaa kayak mobillah, mobil sekarang plat 0,5 0,7 memang dia efisien mesinnya ringan pake alumunium aloy, tapi dibikin jangka waktunya ngga sampe 20 tahun malah, paling 10 tahun udah bagus itu orang kadang chiler yang barunya malah suka watuk, ngambek ko.(N1,01/02/19) 
Berdasarkan kutipan di atas dapat di simpulkan bahwa dalam proses perencanaan dan pengadaan AC di Masjid Baitul Ihsan Bank Indonesia Surabaya itu sepenuhnya di fasilitasi oleh Bank Indonesia Surabaya, dengan begitu para pegawai dan khususnya teknisi yang bertugas hanya mengoprasikan, mengontrol dan melakukan perawatan setiap harinya, dan terakait kendala jika ada kerusakan pada $\mathrm{AC}$ dan harus ada pengadaan baru, untuk melapor terlebih dahulu ke kantor pusat di Jakarta. Karena AC ini termasuk ke dalam nilai investasi dan sprepart pada unit AC Central ini memakan biaya yang cukup besar, BI juga sudah bekerjasama oleh beberapa perusahaan yang dapat menangani jika ada kerusakan pada unit AC, jadi dalam hal ini teknisi yang bertugas di dalam gedung hanya mengoprasikan dan melakukan perawatan sederhana setiap harinya.

\section{Pengorganisasian (organizing)}

Pengorganisasian merupakan pengelompokan kegiatan-kegiatan kemasjidan dalam kesatuan-kesatuan tertentu, menetapkan para pelaksana yang kompeten pada kesatuankesatuan tersebut serta memberikan wewenang dan jalinan hubungan di antara mereka. Yang dimana perencanaan dilakukan oleh sumber daya manusia, dan pihak-pihak yang telah diajak bekerja sama. Pada tahap pengorganisasian pihak BI telah menentukan pihak-pihak terkait fasilitas AC di Masjid Baitul Ihsan, dalam hal ini melibatkan beberapa perusahaan besar.

"Kalo untuk AC pengorganisasianya merekakan kontrak dengan kita jadi diluar organisasian ini krekanan yang sekarang berjalan itukan PT.yuawana karya yaa, PT.catur manunggal yang terkait pemeliharaan AC itu mereka punya organisasi sendiri di luarnya BI tapi dengan BI ada MOU ada kontrak ada perjanjian ada SPK.

Berdasarkan kutipan di atas dapat di simpulkan bahwa Masjid Baitul Ihsan Bank Indonesia Surabaya dalam sistem pengorganisasiannya melibatkan pihak-pihak terkait untuk memenuhi kebutuhan fasilitas AC di BI,antara lain PT. Yuawana Karya dan PT.Catur Manunggal, dalam hal ini 2 perusahaan tersebut di kontrak terkait sistem perawatan dan pengadaan unit $\mathrm{AC}$ jika terjadi kerusakan, tetapi kedua perusahaan ini memiliki organisasi sendiri di luar BI, jadi dengan BI sudah ada MOU atau kontrak jika unit AC bermasalah.

\section{Humazing (SDMisasi)}

Humas adalah kegiatan untuk membuat semua pengurus mengetahui kewajiban, tugas, wewenang dan tanggung jawabnya sebagai pengurus masjid yang menjadi teladan bagi jamaah masjid dan masyarakat sekitar dalam mengemban amanah manajemen. Dalam proses humas atau pengembangan SDM takmir atau bagian logistic Masjid Baitul Ihsan sudah memberikan pengarahan kepada teknisi jika ada malasah pada AC, dan menngikuti sesuai dengan prosuder yang telah dibuat.

"Kita mulai oprasional itu jam 6 pagi terus offnya itu jam 5 sore, tapi kalo ada acara kita tetep oprasional, yang jelas kondensornya, pasti kotor utama pasti kondensor abis itu fan motor,eemm kalo bersihin tiap hari ngga, kalo tiap hari ngeceknya itu sensor sama temperaturnya, kalo untuk perawatan 2 bulan sekali, kalo operasi sama kontrolnya saya, kendala paling sering sensor, itu kendali paling sering sih, paling kecil dan paling sering, paling kecil resikonya , paling sering terjadi tuh di 
sensor, sensor yaa buat temperature, itu sistemnya jadi satu mas, jadi kalo ada satu sensor satu yang mati yang lainya ngga mau jalan kendala paling sering, kalo mengatasi kendala, kita report dulu mas, nanti pak didit bikin mungkin atau ada penawaran dulu dari vendor lainkan kalo perbaikan kita ngga bisa mas kalo perbaikan tuhh vendor lain bukan kita, kita Cuma mendampingi, tiap hari kita control ada trouble kita report nanti dari pak didit ada langkah selanjutnya dari vendor lain baru bisa menangani."

Berdasarkan hasil kutipan di atas dapat di simpulkan bahwa Masjid Baitul Ihsan Bank Indonesia sudah cukup baik dalam sistem humasnya, karena para staf atau teknisi AC di Masjid Baitul Ihsan sudah menjalankan tugasnya dengan baik dan sesuai dengan ketetapan yang telah disepakati, mereka juga harus hadir tepat waktu, karena kira-kira durasi untuk mendinginkan ruangan itu sekitar 30 menit, para teknisi juga harus hadir ketika ada acara lain di luar jam kerja pegawai BI dan ketika ada kerusakan pada unit AC itu harus melapor terlebih dahulu kebagian logistic, karena tugas utama dari teknisi AC di BI adalah mengoprasikan dan

melakukan perawatan-perawatan sederhana.

\section{Actuating (Penggerakan)}

Penggerakkan adalah kegiatan menggerakkan para pelaksana untuk menyelenggarakan setiap kegiatan kemasjidan dengan memanfaatkan sumber daya yang ada secara efektif dan efisien untuk mencapai hasil yang maksimal. Dalam melakukan penggerakan ini peran kepemimpinan sangat besar. Berdasarkan hasil observasi di peroleh data terkait pelaksanaan kegiatan atau program-program yang mulai di terapkan di Masjid Baitul Ihsan Bank Indonesia Surabaya.

jadi 3 program unggulan yang permintaan dari kantor pusat itu bagi pegawai Muslim itu wajid sebenernya sifatnya Cuma wajib disinikan persuasifnya tuhkan jangan sampai paksaan yaa istilahnya kita membangun kesadaran dengan persuasif supaya mereka mereka ini yang belum, contoh belum mau shalat belum mau tolabul ilmi jadi membangun keikut sertaan pegawai ini dengan cara cara yang hikmahlah intinya itu, itu ada 3 program yang peratama shalat berjaamah di masjid kalo di kantor kita setidaknya 2 waktulah dzhur dan asar syukur syukur bisa magrib tapi kebanyakan dhuzur dan asar dan Alhamdulillah kalo diliat dari perkembangannya yaa sampai 4 saff 5 saff awalnyakan 2 saf karena juga yang ngawali pimpinan kan pimpinan disini juga kadang ngimamin untuk shalat shalat yang imam non jaher yaa, kemudian program yang kedua yaitu NGABARI istilahnya (ngaji bareng pegawai ) ya ini masih kita susun untuk pendaftarannya setealh ini kita mungkin manggil ustad atau narasumber dari mungkin griya quran atau dari alfalah atau dari STIDKI kalo mungkin bersedia membimbing kami, Cuma 2 kelas saja yang kita buka yaitu kelas tilwati atau kelas pemula atau kelas yang sudah bisa baca Al-Quran yang ketiga ngaji tafsir atau ngaji tematik kalo di kantor pusat ngaji tafsir bisa ngambil dari ee tafsir 
ibnu katsir itu di kaji dalami kemudian eee pegawai supaya ngertilah intinya walaupun waktunya mungkin sebentar yaa dan ini kita juga masih musyawarah untuk waktunya supaya ngga ganging pekerjaan samaa keluarga, karna waktu yang di BI inikan cukup padet yaaa kalo dari sesi kinerja dan kita masih musyawarah dengan mereka yang telah mendaftar

Berdasarkan dari hasil kutipan diatas dapat di simpulkan bahwa dalam proses penggerakkan untuk menyukseskan program program yang telah dibentuk untuk staf dan pegawai itu sangat membuntuhkan peran seorang pemimpin, dan dalam hal ini pihak BI sudah mulai mengaktifkan program yang telah di sepakatinya, dan untuk menyukseskan program-program tersebut sangat di butuhkan juga keikut sertaaan para pegawai. Alhamdulillah karena ini adalah program perminta yang di ajukan dari pihak pusat, pimpinan juga yang langsung mengawali untuk memberikan contoh kepada bawahannya. Karena peran seorang pemimpin sangat berpengaruh bagi bawahanya. Di harapkan dari program ini para pegawai bisa lebih rajin beribadah dan memakmurkan masjid. Semua program ini juga tidak bersifat wajib, lebih bersifat persuasive, karena tujuan utamanya adalah untuk membangun kesadaran para pegawai agar lebih sering memakmurkan masjid.

\section{Controling (Pengawasan)}

Pengawasan adalah kegiatan untuk mengawasi agar setiap kegiatan dan tindakan yang dilakukan pelaksana tugas-tugas kemasjidan dilakukan sesuai dengan pedoman dan ketentuan-ketentuan yang telah ditetapkan, baik secara hukum syar'i maupun berdasarkan perundang undangan yang berlaku. Jadi pengawasan bukanlah kegiatan mencari-cari kesalahan, tapi kegiatan memastikan bahwa semua pelaksana tugas kemasjidan menjalankan tugasnya sebaik mungkin.

Jadi kalo untuk prosedurnya kita sendirikan juga ngurusin gedung ya, yang ngurusin gedung disinikan ada 4 ya, ada bapak jazuli, mas bagus, mba eka, sama saya terus di atasnya itu ada pa stiono menejer di gedung inikan banyak yaa, jadi melalu sipil arsitektur tehnikal elektrikel kemudian landscape atau streaming ya terus prabot dan ngurusin juga tagihannya itu juga di urus juga, itu kalo ada masalah contohnya di AC itukan biasanya kita komunikasinya melalui $\mathrm{Ht}$ atau hp atau WA terus dari tehnisi ngabarkan atau ngasih info ada kerusakan di sistem ini dan kerusakan mesin, kita turun ngecek apakah benar ada kerusakan, apakah masih di perbaiki oleh teman teman on the spot, kalo bisa monggo di perbaiki kita terbitkan surat tugas, kemudian kalo ngga bisa kita naikkan ke principal yang punya barang, jadi yang punya barang itukan juga punya kantor yang di Surabaya juga jadi kita ngabari terus seluruh proses, karena itukan di luar SPK ya penggantia penggantian itukan di luar kontrak ya karena mereka hanya pemeliharaannya saja sama monitoring, jadikan menginfokan yang rusak tuh apa sprepartnya tuh apa terus kalo memang bisa di tangani sendiri oleh temen temen nanti kita terbitkan kayak semacam PO atau SPOK

Berdasarkan kutipan di atas dapat di simpulkan bahwa dalam proses controlling di Masjid Baitul Ihsan Bank Indonesia Surabaya cukup banyak melibatkan orang, karena gedung BI ini cukup besar di bentuklah beberapa bagian seperti melalui sipil arsitektur,tehnical electrical kemudian landscape,streaming dan juga ada yang bertanggung 
jawab terkait prabotan dan tagihan, jadi dalam hal ini seorang menejer hanya memantau jika ada laporan dari bawahan, dan untuk berkomunikasi bisa via HP atau HT jika terjadi kerusakan khususnya pada unit AC, ketika laporan masuk ke bagian logistic, pihak logistic akan langsung melihat apakah benar ada kerusakan, jika kerusakan masih dapat di tangani oleh teknisi yang bertugas maka akan dibuatkan surat tugas dan persilahkan untuk memperbaikinya, dan jika tidak bisa maka pihak logistic akan melaporkan ke kantor pusat agar di terbitkan semacam PO atau SPOK.

\section{Integrating (Penyatu-paduan)}

Seringkali fungsi-fungsi kerja yang berada dalam suatu manajemen masjid terlalu fokus dengan pekerjaannya sendiri. Oleh karena itu setiap penanggung jawab kerja kemasjidan perlu diingatkan di awal bahwa memiliki tanggung jawab yang berbeda namun memiliki tujuan yang sama, yaitu memakmurkan masjid. Dalam hal ini cukup terbilang sulit karna hampir semua pengurus Masjid Baitul Ihsan adalah pegawai di gedung BI.

"Kalo masjid struktur organisasinya itukan di bawahnya ikatan pegawai bank Indonesia (IPBI). Dari (IPBI) sendiri ada satu Sie. Yaitu sie.kerohanian islam (SKI) kemudian dibawahnya (SKI) itu membawahi manajemen masjid yang ada di lantai 2 itu untuk majemen masjid sendiri ada struktur organisasi lagi, antara lain ada takmir terus kemudian ada bendahara masjid,skretaris terus kemudian eeee imam ya dan imam disitu sebenernya juga dia juga sebagai manager dalam arti pengelolaan ya semacam kalo di luar itu kayak (IO) lah, itu memenej khotib-kohtib yang dari luar,penjadwalan,terus kemudian eee dia juga yang menghubungi khotib khotibnya juga kalo kondisi misalkan belum datang ada masalah apa terus juga yang bagian marbot atau bagian kebersihan masjid. Sebenernya ngga terlalu banyak sih ininya eess strukturnya ngga terlalu rinci juga sih, kalo untuk paling dari (IPBI), (IPBI) itukan ketuanya kalo disini ketuanya pak suhari kominsaris surbaya membawahin banyak sei tuh, olah raga kesenian kemudian kerohanian kerohanianya kan macem macem paling gede kan islam terus kemudian keristen hindu budha kathokik kemudian eeeada lagi sei untuk masjid sendirikan di bawahnya SKI itupun minimal struktur itu kan memang bisa berubah jadi eee ngga harus istilahnya saklek tergantung dari ee keaktifan dari pegawainya sendiri terus kalo misalkan pegawainya mutasi ya kita berubah sebelum saya kan sebelumnya yang megang sayakan dalam kerohanian islam kan itu namanya pak yasin, pak yasin sudah bagus sih, beliau soalnya waktu senggangnya juga lebih banyak dari pada saya terusss waktu untuk memeikirkan yaa memikirkan program- program masjid juga lebih longgar kalo yang megang yang megang pegawai terus itu tugas pokoknya itu lebih tinggi ya biasanya yaaa ngga terlalu ini sih apa itu selalu intens untuk ngurusin masjid makanya perlu adanya kayak pengelola dan manajer masjid kalo sekarang ini kan di jabat oleh ustad nasrulloh, ustad nasrullah itu juga dulunya hasil sleksi bukan maen comot kyak sebelum sebelumnya kita maen comot.

Berdasarkan dari hasil wawancara di atas, dapat diketahui bahwa Masjid Baitul Ihsan Bank Indonesia Surabaya cukup kesulitan dalam mengelola dan menghidupkan masjid, karena masjid menyatu dengan gedung Bank Indonesia maka kebanyakan dari pengurus di 
Masjid Baitul Ihsan adalah pegawai BI, cukup sulit karena amanah pekerjaan kantor dan kemasjidan, oleh karena itu mungkin amanah atau tanggung jawab di masjid lebih bersifat fleksibel, jadi segala kegiatan di masjid bisa terbilang cukup minim, oleh karena itu pihak BI memutuskan untuk mencari orang khusus yang hanya focus di bidang ke masjidan, dari hasil seleksi se Jawa Timur akhirnya terpilihlah seorang imam sekaligus maneger masjid, mulai saat itu segala program masjid di serahkann pada imam masjid atau meneger masjid, tidak lupa juga seorang pemimpin atau ketua takmir yang meluangkan waktunya untuk mengontrol segala kebutuhan dan program program yang mulai berjalan agar tetep sesuai dengan tujuannya. Alhamdulillah dengan hadirnya imam sekaligus manejer masjid, program-program mulai lebih tertata dan aktif. Dan tak lupa di dorong dari kesadaran para pegawai untuk lebih berperan aktif demi kemakmuran masjid.

\section{Evaluating (Evaluasi)}

Evaluasi adalah proses pengukuran, penilaian, dan analisis terhadap kinerja yang dilakukan serta pengambilan kesimpulan tentang ada atau tidaknya kesesuaian dengan tujuan dan penyebab-penyebabnya untuk dijadikan dasar dalam melaksanakan tindak lanjut. Dalam hal ini Masjid Baitul Ihsan melakukan evaluasi untuk mengetahui apa saja yang perlu diperbaiki, dari data yang di peroleh dari narasumber dapat diketahui dalam pelaksanaan evaluasinnya. Setelah melakukan perawatan, maka dilakukan pengecekan apakah dalam jangka yang cukup panjang ini ada masalah pada mesin ataupun teknisi yang bertugas.

Evaluasi tiap taun tiap menjelang akhir kontrak kita tetep evaluasi juga ee kita sudah 2 kalo ngga 3 priode tuh rekanan yang sama, kenapa dengan rekanan yang sama karena mereka juga sudah punya tenaga yang memadai karnakan yang mereka pegang tidak hanya ac central tok seluruh ac ac split seluruh gedung kantor kemudian eeee perpustakaan, kantin itukan kita juga kontrak dengan merekan juga jadi kalo nanti memang ada indikasi indikasi yang tidak pas ya kita ganti Cuma memang kalo ganti rekanan itu yaa kita mulai dari nol lagi karna merekakan baru, jadi penyusuain ruangan terus kita harus ngawasinya juga harus lebih intens, karena mereka belum tau posisi posisi unit unit yang ada di gedung kantor kemudian di perpustakaan.

Berdasarkan dari hasil wawancara di atas dapat diketahui bahwa takmir atau bagian logistic Masjid Baitul Ihsan melakukan evaluasi setiap setaun atau setiap akhir kontrak dan Alhamdulillah sudah sekitar 2-3 priode masih dengan rekanan yang sama, mereka juga sudah sangat mengetahui kondisi lapangan, karena jika mengganti dengan yang baru mungkin harus ada waktu untuk beradaptasi, karena bukan hanya AC central saja, melainkan AC split dan itu jumlahnya sangat banyak dan aksesnya juga tidak mudah. Karena gedung BI memiliki banyak ruang, contohnya seperti perpustakaan,kantin,masjid dan yang utama ruang ruangan kantor pegawai BI.

\subsection{Analisis Data}

Pada pembahasan ini dibahas terkait data atau hasil temuan yang didapatkan oleh peneliti dilapangan dengan cara mengkonfirmasikan dengan teori yang sudah ada. Dalam 
penelitian kualitatif, pada dasarnya harus melahirkan teori baru, akan tetap jika tidak memungkinkan teori yang sudah ada dengan data penemuan yang kita dapatkan di lapangan,

Analisis data yang digunakan oleh peneliti adalah analisi deskriftif kualitatif, yaitu suatu metode yang berusaha mendeskripsikan yang diteliti dengan melukiskan dan mengklarifikasi fakta atau karakteristik tersebut secara faktual dan cermat untuk memberikan gambaran yang jelas atau akurat tentang fenomena yang diselidiki. Peneliti berusaha menganalisis secara singkat dan jelas mengenai manajemen fasilitas air conditioner di Masjid Baitul Ihsan Bank Indonesia Surabaya.

\section{Planning (perencanaan)}

GR. Terry sebagaimana yang dikutip Sutadji menjelaskan bahwa perencanaan merupakan bagian penting dalam manajemen. Perencanaan adalah kegiatan memilih dan menghubungkan fakta-fakta dan membuat serta menggunakan asumsi-asumsi tersebut untuk menyusun sesuatu di masa yang akan datang dengan jalan menggambarkan dan merumuskan kegiatan kegiatan yang diperlukan untuk mencapai hasil yang diinginkan.

Di dalam perencanaan atau pengadaan ini, pasti terdapat tahap-tahap terkait dana pengadaan unit AC,karena AC central bisa dibilang sangat mahal, hal tersebut sesuai dengan keterangan dari beberapa narasumber, antara lain :

"Untuk pengadaan yaa,jadi untuk perencaaan sistem pendingin gedung itu,kalo di kitakan karna AC nya sudah ada tuh berartikan pemeliharaanya tetep ada kontrak tetep ada,planning tetep ada, sistemnya kayak tender untuk pemeliharann,namun untuk pengadaan karana umurnya AC central itukan mirip mirip sama umurnya gedung kantor kurang lebih 20 tahun untuk ac central itu maksudnya untuk ganti baru jadi mesti atau aturan dikita kurang lebih 20 tahun itu pengadaannya melalui kantor pusat pengadaan baru, kalo pengadaaan baru ya, karena kenapa kantor pusat, pertama nilainya itu masuk ke nilai investasi, kan AC central itu harganya kan ngga cukup 100-200 juta, satu chiler itu harganya pas saya masuk di BI itu tahun 2012 itu haraganya satu itu harganya 1 komaa, 1,5 M itu baru 1, belum lagi nanti kalo 5, itu harga pada saat tahun itu, yakan liat dari kondisi upahnya berapa terus dolarnya berapakan gitu jadi nilai kayak gitu sudah wewenangnya kantor pusat apalagi merombak seluruh instalasi jadi model tendernya lelang tapi di bikin model paket karna nilainya cukup gede kalo di tafsir sih untuk chilernya aja misalkan $2 \mathrm{M}$ yaa $2 \times 5$ $10 \mathrm{M}$ belum instalasi, belum AHUnya kira kira di atas 10M. Sebelum pengadaan tetep ada assesement dari tim kantor pusat dan mungkin dari upraisor atau dari rensalten ini kira kira masih layak atau ngga soalnya mohon maaf barang barang sekarang kwalitasnya tuh beda sama barang barang dulu contoh kwalitas plat yaa kayak mobillah, mobil sekarang plat 0,5 0,7 memang dia efisien mesinnya ringan pake alumunium aloy ,tapi dibikin jangka waktunya ngga sampe 20 tahun malah, paling 10 tahun udah bagus itu orang kadang chiler yang barunya malah suka watuk, ngambek ko. 
Diketahui bahwa terkait perencanaan atau pengadaan unit AC di Masjid Baitul Ihsan adalah fasilitas yang di berikan langsung dari gedung BI, dengan adanya perencanaan atau pengadaan tersebut takmir masjid dan bagian logistic hanya memperhatikan terkait perawatannya,dalam hal ini sudah sesuai dengan prosedur.

\section{Organizing (pengorganisasian)}

Menurut Dirjen Bimas Islam dan Urusan Haji, Depag (2000: 3) Organizing adalah pengelompokan kegiatan-kegiatan kemasjidan dalam kesatuan-kesatuan tertentu, menetapkan para pelaksana yang kompeten pada kesatuan-kesatuan tersebut serta memberikan wewenang dan jalinan hubungan di antara mereka.

Berdasarkan definisi tadi, maka pelaksanaan organizing berawal dari perencanaan dan menghasilkan Struktur Organisasi beserta 2 perangkat terkait lainnya yaitu Job Specification dan Job Description. Pada prinsipnya, apa-apa yang hendak dilakukan harus dikelompokkelompokkan terlebih dahulu, ditentukan siapakah orang yang berkompeten melaksanakannya, serta bagaimana cara mengerjakannya. Dalam hal penyajian hasil penyusunan Struktur Organisasi dalam bentuk "Bagan" atau "Organigram", bisa juga berbentuk "Susunan secara berurutan".

Dapat diketahui bahwa proses pengorganisasian terkait peratawan AC di Masjid Baitul Ihsan Bank Indonesia Surabaya berjalan dengan baik, semua perusahaan yang memiliki kontrak dengan BI sudah mempunyai organisasi sendiri tetapi dengan BI masih terikat dengan MOU yang telah di sepakati.

\section{Humazing (SDMisasi)}

Humanizing atau pemberdayaan SDM adalah kegiatan untuk membuat semua pengurus mengetahui kewajiban, tugas, wewenang dan tanggung jawabnya sebagai pengurus masjid yang menjadi teladan bagi jamaah masjid dan masyarakat sekitar dalam mengemban amanah manajemen. Proses ini bisa dilakukan dengan melakukan sosialisasi dan diskusi antara ketua pengelola masjid dengan para pengurusnya untuk memahami job description masing-masing dalam struktur organisasi yang telah disusun dalam tahap organizing. Dalam diskusi tersebut, para pengurus mendalami tugas dan wewenangnya masing-masing serta bagaimana teknis yang terbaik untuk menjalankan tugas dan wewenang tersebut. Hasil dari diskusi adalah pemahaman apa yang akan dilakukan. Sehingga proses humanizing ini merupakan kegiatan yang menjembatani antara organizing dengan actuating. Bahkan kegiatan humanizing bisa digunakan untuk membangun komitmen dan kesungguhan para pengurus sebelum menjalankan tugas dan wewenangnya. ${ }^{3}$

Dapat diketahui bahwa proses humas atau pengembangan SDM di Masjid Baitul Ihsan Bank Indonesia Surabaya berjalan dengan baik, para teknisi yang bertugasa sudah diberikan arahan atau pembekalan agar mengetahui bagain bagian mana saja yang harus dilakukan perawatan. Dalam hal ini khususnya pada unit AC.

\section{Actuating (Penggerakan)}

Suherman mengutip pengertian actuating atau penggerakan dari buku Panduan Kegiatan Kemasjidan dengan menyebutkan bahwa actuating adalah kegiatan menggerakkan para pelaksana untuk menyelenggarakan setiap kegiatan kemasjidan dengan memanfaatkan

\footnotetext{
${ }^{3}$ Eman Suherman. Manajemen Masjid, (Bandung: Alfabeta, 2012) hlm 93.
} 
sumber daya yang ada secara efektif dan efisien untuk mencapai hasil yang maksimal. Dalam melakukan penggerakan ini peran kepemimpinan sangat besar. Untuk ini, dimungkinkan untuk mengadakan rapat-rapat koordinasi menjelang dilaksanakannya suatu kegiatan kemasjidan. Bahkan jika kegiatan kemasjidan itu memiliki kompleksitas yang cukup tinggi bisa dilakukan dengan pembentukan panitia pelaksana kegiatan. Dalam pelaksanaannya, pemimpin harus bisa menjelaskan secara gamblang job description tiap pelaksana agar tidak terjadi tumpang tindih. Tidak hanya itu, pemimpin juga harus mengambil peran langsung dengan mengarahkan pelaksanaan sesuai dengan yang direncanakan. ${ }^{4}$

Dari pembahasan di atas dapat diketahui bahwa bagian logistic Masjid Baitul Ihsan Bank Indonesia Surabaya memiliki tugas untuk mengontrol dan memberikan arahan kepada teknisi jika ada unit AC yang bermasalah dalam hal ini pihak logistic sudah malaksanakan tugasnya dengan baik dan benar.

\section{Controling (Pengawasan)}

Controlling atau pengawasan adalah kegiatan untuk mengawasi agar setiap kegiatan dan tindakan yang dilakukan pelaksana tugas-tugas kemasjidan dilakukan sesuai dengan pedoman dan ketentuan-ketentuan yang telah ditetapkan, baik secara hukum syar'i maupun berdasarkan perundang undangan yang berlaku. Jadi pengawasan bukanlah kegiatan mencaricari kesalahan, tapi kegiatan memastikan bahwa semua pelaksana tugas kemasjidan menjalankan tugasnya sebaik mungkin. Cara yang dilakukan tentu harus dengan menggunakan komunikasi yang baik, bil hikmah. Dalam menjalankan pengawasannya, pihak ketua pelaksana atau ketua takmir bisa melakukan motivasi kepada bawahannya, menanamkan nilai-nilai keakhiratan sebagai pondasi kerja para petugas kegiatan masjid. ${ }^{5}$

Dari pembahasan diatas dapat disimpulkan bahwa proses controlling di Masjid Baitul Ihsan Bank Indonesia Surabaya sudah berjalan dengan baik karena sudah sesuai dengan prosuder yang telah disepakati contohnya ketika terjadi kerusakan pada unit AC maka pihak teknisi akan melapor kebagian logistic, dan pihak logistic akan langsung melakukan pengecekan ke TKP jik benar, maka pihak logistic akan membuat surat laporan ke kantor pusat.

\section{Integrating (Penyatu-paduan)}

Seringkali fungsi-fungsi kerja yang berada dalam suatu manajemen masjid terlalu fokus dengan pekerjaannya sendiri. Oleh karena itu setiap penanggung jawab kerja kemasjidan perlu diingatkan di awal bahwa memiliki tanggung jawab yang berbeda namun memiliki tujuan yang sama, yaitu memakmurkan masjid. ${ }^{6}$

Dari pembahasan di atas dapat dimpulkan bahwa terkait penyatu paduan takmir Masjid Baitul Ihsan sudah terlaksana dengan baik, karena kebanyakan pengurus takmir Masjid Baitul Ihsan adalah pegawai BI, dalam hal ini para pengurus bisa menjalankan amanahnya dengan baik dan mengikuti sesuai dengan prosedurnya, tanpa menggangu kewajibannya sebagai pegawai kantor.

\section{Evaluating (Evaluasi)}

\footnotetext{
${ }^{4}$ Ibid.,hlm 94.

5 Ibid., hlm 95.

${ }^{6}$ Ibid., hlm 96-97.
} 
Menurut Suherman, evaluating adalah proses pengukuran, penilaian, dan analisis terhadap kinerja yang dilakukan serta pengambilan kesimpulan tentang ada atau tidaknya kesesuaian dengan tujuan dan penyebab-penyebabnya untuk dijadikan dasar dalam melaksanakan tindak lanjut. Evaluasi hendaknya dilakukan secara periodik, berkelanjutan, dan berkesinambungan. Evaluasi diawali dengan melakukan pengukuran terhadap obyek yang dievaluasi. Pada waktu melakukan pengukuran ini tentu harus ada alat ukurnya. Ukuran yang biasa dipakai tentu saja adalah tujuan dan deskripsi tugas (job description). Setelah melakukan pengukuran, maka dilakukan penilaian apakah pelaksanaan bisa dikatakan sukses atau gagal. Selanjutnya dianalisis hal-hal yang menjadi sebab kesuksesan atau kegagalan. Dan diakhiri dengan keputusan tindak lanjut. Hal tersebut dapat di perjelas dari data yang di dapat dari beberapa narasumber, sebagai berikut :

Evaluasi tiap taun tiap menjelang akhir kontrak kita tetep evaluasi juga ee kita sudah 2 kalo ngga 3 priode tuh rekanan yang sama, kenapa dengan rekanan yang sama karena mereka juga sudah punya tenaga yang memadai karnakan yang mereka pegang tidak hanya ac central tok seluruh ac ac split seluruh gedung kantor kemudian eeee perpustakaan, kantin itukan kita juga kontrak dengan merekan juga jadi kalo nanti memang ada indikasi kasi yang tidak pas ya kita ganti Cuma memang kalo ganti rekanan itu yaa kita mulai dari nol lagi karna merekakan baru, jadi penyusuain ruangan terus kita harus ngawasinya juga harus lebih intens, karena mereka belum tau posisi posisi unit unit yang ada di gedung kantor kemudian di perpustakaan.

Dari pembahasan diatas dapat disimpulkan bahwa terkait evaluasi perawatan AC di Masjid Baitul Ihsan terbilang kurang baik, Karena dalam pelaksanaan evaluasi hanya dilakukan setiap setaun sekali dan ketika akhir kontrak, adapun jika terjadi kendala pada teknisi, mungkin akan lebih di pertimbangkan kembali, Karena akan menambah sulit juga melakukan penggantian yang baru.

\section{SIMPULAN}

Manajemen fasilitas AC di Masjid Baitul Ihsan dilakukan mulai dari tahap perencanaan hingga evaluasi. Terdapat beberapa pihak yang terbilat dalam pelaksanaan manajemen fasilitas AC tersebut, yaitu pihak BI, pihak masjid, dan pihak jasa layanan perawatan AC. Koordinasi yang baik membuat performa AC di Masjid Baitul Ihsan berfungsi optimal, sehingga para jama'ah merasa puas.

\section{DAFTAR PUSTAKA}

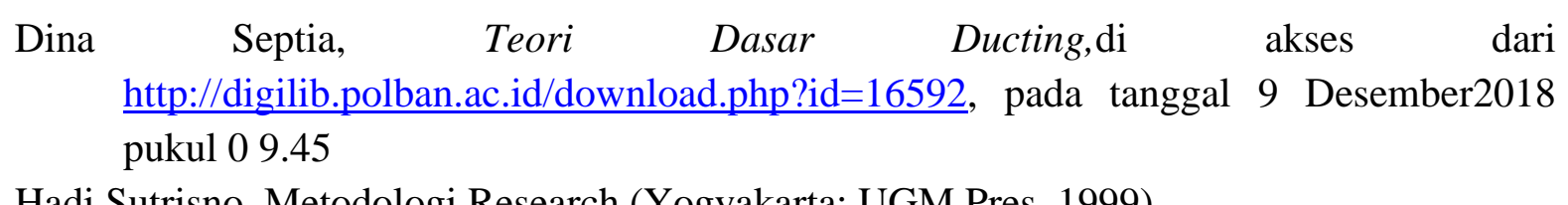

Hadi Sutrisno, Metodologi Research (Yogyakarta: UGM Pres, 1999)

Handoko Juni, Merawat dan Memperbaiki AC, (Jakarta: Kawan Pustaka, 2009) 
Harnadi Irawan Bangun,dkk, Perencanaan Pemeliharaan Mesin Produksi Dengan Menggunakan Metode (RCM). Malang Jurusan Teknik Industri Universitas Brawijaya Jalan MT. Haryono 167

Hasi kerjasama ICMI ORSAT CEMPAKA PUTIH, fokusS Babinrohis dan Yayasan kado anak muslim.Pedoman Manajemen Masjid tahun 2003.

Ismail Usman Asep, dan Castrawijaya Cecep, Manajemen Masjid, (Bandung: Angkasa Bandung, 2010)

Kurniawan Fajar, Manajemen Perawatan Indrustri, Yogyakarta, 2013

Kurniawan Syamsul, "Masjid Dalam Lintasan Sejarah Umat Islam "Journal of Islamic Studies, Vol.4 Nomor 2 September 2014

Martin dan Fuad Nurhattati,Manajemen Sarana dan Prasarana Pendidikan Konsep dan Aplikasinya (Depok: RAJA GRAFINDO PERSADA, 2016)

Maryulina Asnelly Analisis Pemeliharaan Mesin Produksi Pada PT. P\&P Bangkinang di Desa Simalinyang (Pekanbaru: 2010)

Moleong Lexy. J, Metode Penelitian Kualitatif (Bandung: Rosda Karya 2007),

Putri Yuritami Meidita Annisa,Muhidin Ali Sambas, Jurnal Pendidikan Manajemen Perkantoran Survei tentang standar fasilitas pembelajaran di SMK Pasundan 1 Bandung Vol.1 No.2 Januari 2018

Raco,Metode Penelitian Kualitatif, (Jakarta: Grasindo,2010)

Rahardjo Arif Imam "Pelatihan Perbaikan Dan Perawatan Air Conditioner" Jurnal Sarwahita Volume 13 NO. 1.

Rasindyo Riseno Muhammad, Kusmaningrum, Helianty Yanti, jurnal, Analisis Kebijakan Perawatan Mesin Cincinnati Dengan Menggunakan Metode Reliability Centered Maintenance Di PT.Dirgantara Indonesia No.1| Vol.03 Jurnal Online Institut Teknologi Nasional, Januari 2015

Sofyan Lutfi Indra,dkk., Pengaruh Fasilitas dan Kualitas Pelayanan Terhadap Loyalitas, Diponogoro jurnal of social and politic tahun 2013

Sofyan, L.I. dkk. 2013. Pengaruh Fasilitas dan Kualitas Pelayanan Terhadap Loyalitas. Journal of Social and Politic.

Suherman Eman . Manajemen Masjid, (Bandung: Alfabeta, 2012)

Sundusiah Suci,Analisis Data Kualitatif, Makalah Jurusan Pendidikan Bahasa Dan Sastra Indonesia, 2010

Susanto Feri Eko "Otomatisasi Menitoring Air Condition Berbasis Arduino dan SMS Gateway" (sidoarjo,2018)

Syamsudin" Penerapan fungsi-fungsi Manajemen Dalam Meningkatkan Mutu Pendidikan” JURNAL IDAARAH, (VOL. I, NO. 1, Juni 2017)

Thoha, AFK. Mubarrok, H. dan Hakim, A.K. 2019. Strategi Masjid Baitul Ihsan Bank Indonesia Jawa Timur dalam Membangun Loyalitas Murid TPQ. Masjiduna : Jurnal Ilmiah Stidki Ar-Rahmah 2(2): 56-63.

Wawancaara dengan pengurus Masjid Baitul Ihsan Bapak Arifin pada tanggal 19 Oktober 2018, pukul 12.30, bertempat di Masjid Baitul Ihsan 